\title{
Pueblos indígenas y tribales y derechos humanos en la jurisprudencia de la Corte Interamericana de Derechos Humanos: una mirada crítica
}

\author{
Indigenous and Tribal Peoples and Human Rights \\ in the Case Law of the Inter-American Court \\ of Human Rights: A Critical Outlook
}

\section{Les peuples autochtones et tribaux et les droits de l'homme dans la jurisprudence de la Cour Interamericaine des Droits de L'homme: un regard critique}

Felipe Ignacio Paredes Paredes ${ }^{*}$

\begin{abstract}
SUMARIO: I. Introducción. II. Los pueblos indígenas y tribales ante el derecho internacional de los derechos humanos. III. Derechos humanos y problemas de traducción. IV. Derechos humanos, pobreza, desigualdad y exclusión radical. V. Valoración crítica y conclusiones. VI. Bibliografía.
\end{abstract}

* Universidad Austral de Chile, Chile; ORCID ID: https://orcid.org/0000-0003-0232-19 19,felipe.paredes@uach.cl. 
Resumen: La jurisprudencia de la Corte Interamericana de Derechos Humanos ha representado una invaluable contribución en la protección de los pueblos indígenas en América; sin embargo, su desarrollo no ha sido una tarea fácil. Este trabajo busca identificar los principales desafíos y problemas a los que se enfrenta esta jurisprudencia a fin de determinar su impacto en los derechos humanos de las comunidades involucradas. La hipótesis que se plantea es que la jurisprudencia sobre los pueblos indígenas está atravesada por una tensión entre lo ortodoxo y lo original y por un dilema entre lo ambicioso y lo realista que influyen poderosamente en sus efectos sobre los derechos de los pueblos indígenas dentro de los Estados signatarios.

Palabras clave: pueblos indígenas, derechos humanos, Corte Interamericana de Derechos Humanos.

ABSTRACT: The case-law of the Inter-American Court of Human Rights has had an invaluable contribution to the protection of indigenous peoples in the Americas. However, its development has not been an easy task. This paper aims to identify the main challenges and problems that this case-law has faced with evaluating their impacts on the human rights of the communities involved. Indeed, the case-law on indigenous peoples is crossed by the tension orthodoxy-originality and by a dilemma between an ambitious and another more pragmatic approach. This circumstance influences its effects on the rights of indigenous peoples inside the legislation of the signatory States powerfully.

Key words: indigenous peoples, human rights, Inter-American Court of Human Rights.

RÉSUMÉ: La jurisprudence de la Cour interaméricaine des droits de l'homme a représenté une contribution inestimable à la protection des peuples autochtones en l'Amérique. Cependant, cette tâche n'a pas été facile. Cette recherche vise à identifier les principaux défis et problèmes auxquels est confrontée cette jurisprudence, afin de déterminer leur impact sur les droits humains des communautés concernées. L'hypothèse à l'étude, est que toute la jurisprudence sur les peuples autochtones est traversée par une tension entre l'orthodoxe et l'original et aussi pour un dilemme entre une approche ambitieux et autre plus réaliste, ce qui influe fortement sur ses effets sur les droits des peuples autochtones dans les États signataires.

Mots-clés: peuples autochtones, droits de l'homme, Cour Interaméricaine des Droits de L'homme. 


\section{INTRODUCCIÓN}

La Corte Interamericana de Derechos Humanos (Corte IDH) ha sido un órgano internacional que ha mostrado una alta sensibilidad para con las reivindicaciones de los pueblos indígenas y tribales. Su jurisprudencia ha definido una serie de estándares que constituyen importantes contribuciones a la protección de dichos pueblos. En el continente americano existen países que han prestado mayor atención al reconocimiento jurídico de sus pueblos originarios y tribales; por ejemplo, Colombia, Bolivia o Ecuador. Sin embargo, en otros Estados dicho reconocimiento es inexistente o posee aún un carácter muy incipiente.

La importancia del tema se explica por sí misma. En América Latina estos pueblos son un componente esencial de sus sociedades. Según el Fondo de las Naciones Unidas para la Infancia (Unicef), en el continente existen, actualmente, 522 pueblos indígenas. Por países, Brasil es el que posee mayor diversidad, con 241; le siguen Colombia, con 83; México, con 67, y Perú, con 43. Por otra parte, Bolivia, Guatemala y Belice se sitúan como los países donde los indígenas representan porcentajes más altos sobre la población total, con un aproximado del $66.2 \%$, el $39.9 \%$ y el $16.6 \%$, respectivamente. Aunque ese porcentaje puede ser variable; en la mayoría de los países mencionados la población indígena va del 3\% al 10\% del total de ciudadano. ${ }^{1}$

Por otra parte, éstos se encuentran entre los grupos más vulnerables, desfavorecidos y marginados del mundo. Para el Fondo Internacional de Desarrollo Agrícola de la Organización de las Naciones Unidas (ONU), constituyen el 15\% de los pobres del mundo y un tercio de los extremadamente pobres. Asimismo, los pueblos indígenas y tribales han sido víctimas del colonialismo. Históricamente, han visto sus tierras arrebatadas, sus recursos expropiados, su población reducida a través de la guerra y la enfermedad y se han visto obligados a aceptar las leyes y políticas de los Estados hegemónicos. ${ }^{2}$

1 Unicef, Atlas sociolingüistico de pueblos indígenas en América Latina, 2020, passim.

2 Burger, Julian, “La protección de los pueblos indígenas en el sistema internacional”, Derechos humanos de los grupos vulnerables, Barcelona, Universitat Pompeu Fabra, 2014, pp. 213-239. 
La jurisprudencia de la Corte IDH en esta materia es de una data relativamente reciente $y$, además, se caracteriza porque la Corte IDH ha debido emplear una dosis importante de creatividad en su desarrollo. ${ }^{3}$ A primera vista, la causa sería que los tratados fundacionales del Sistema Interamericano de Derechos Humanos (SIDH) no contienen ninguna referencia expresa a los pueblos indígenas y tribales. Esto se explica por una razón histórica: cuando en 1969 se aprobó la Convención Americana de Derechos Humanos (CADH), no existía consenso sobre el reconocimiento de derechos humanos de grupos específicos, como excepción al principio de la titularidad universal. Incluso décadas después, cuando se aprueba la Declaración de las Naciones Unidas sobre los Derechos de los Pueblos Indígenas, en 2007, la controversia sigue abierta. En dicha oportunidad, Estados Unidos, Canadá, Australia y Nueva Zelandia expresaron importantes reservas al texto de la declaración. ${ }^{4}$

Sin desconocer su invaluable aporte, este trabajo estudia dos de los principales problemas asociados a la protección de los derechos humanos de estos grupos en la jurisprudencia de la Corte IDH. Como se detallará más adelante, estos problemas son la cuestión de las especificidades culturales y la situación de exclusión radical, presentes casi siempre en estos casos. Precisamente, la forma como la Corte IDH ha enfrentado dichos problemas permite explicar el porqué esta línea jurisprudencial parece tan novedosa a los ojos de una teoría estándar de los derechos humanos, excediendo de un simple problema de integración de un vacío normativo. Esos problemas exponen a la Corte IDH a una permanente tensión, la que normalmente debe resolverse asumiendo que no siempre es posible obtener una respuesta óptima a partir del contenido de los tratados. Esta circunstancia representa también el principal riesgo para que tales sentencias puedan producir efectos verdaderamente transformadores en el continente.

Así pues, el trabajo se estructura con base en las siguientes secciones: ii) un análisis de las interacciones entre derecho internacional y derecho interno en relación con los pueblos indígenas y tribales; iii) un estudio de los pro-

3 Rodríguez-Piñeiro, Luis, "El sistema interamericano de derechos humanos y los pueblos indígenas”, en Berraondo, Mikel (coord.), Pueblos indígenas y derechos humanos, Bilbao, Universidad de Deusto, 2006, pp. 153-203.

4 Engle, Karen, "On Fragile Architecture: The UN Declaration on the Rights of Indigenous Peoples in the Context of Human Rights”, The European Journal of International Law, vol. 22, núm.1, 2011, pp. 141-163. 
blemas derivados de las diferencias culturales presentes en la jurisprudencia sobre pueblos indígenas y tribales; iv) un estudio de los problemas que provienen de la situación de exclusión radical que enfrentan dichas comunidades, y v) se finaliza con una última valoración, a modo de conclusiones.

\section{LOS PUEBLOS INDÍGENAS Y TRIBALES ANTE EL DERECHO INTERNACIONAL DE LOS DERECHOS HUMANOS}

Los pueblos indígenas y tribales han recurrido frecuentemente a la Corte IDH para subsanar la situación de injusticia estructural a la que se encuentran sometidos en muchos países. El primer antecedente fue Aloeboetoe y otros vs. Surinam (1991), aunque el verdadero primer hito fundamental vendría 10 años después, con Comunidad Mayagna (Sumo) Awas Tingni vs. Nicaragua (2001). Para este estudio se analizaron todas las sentencias de la Corte IDH que presentan como especificidad la cuestión indígena y tribal, utilizándose como base el trabajo de Estupiñan e Ibáñez, ${ }^{5}$ y agregando las sentencias que a criterio del autor se refieren a esta cuestión con posterioridad. ${ }^{6}$

El recurso al derecho internacional de los derechos humanos es un patrón que también siguen otros grupos vulnerables dentro del SIDH. La experiencia ha demostrado que, ante la insuficiencia de los mecanismos internos, el SIDH ha sido un camino siempre abierto, a pesar de que sus órganos carecen de facultad de imperio para forzar el cumplimiento de sus decisiones. En términos generales, los órganos internacionales se limitan a monitorear cómo los Estados implementan sus obligaciones internacionales, requiriendo, en parte importante, la colaboración del Estado infractor. ${ }^{7}$

5 Estupiñan, Rosmerlin e Ibáñez, Juana, “La jurisprudencia de la Corte Interamericana de Derechos Humanos en materia de pueblos indígenas y tribales”, Derechos humanos de los grupos vulnerables, Barcelona, Universitat Pompeu Fabra, 2014, pp. 301-336.

6 Son las siguientes: Comunidades afrodescendientes desplazadas de la cuenca del río Cacarica (2013); Madungandí y Emberá de Bayano vs. Panamá (2014); Pueblos Kaliña y Lokono vs. Surinam (2015); Comunidad Garifuna de Punta Piedra y sus Miembros vs. Honduras (2015); Comunidad Garífuna Triunfo de la Cruz y sus Miembros vs. Honduras (2015); Pueblo Indígena Xucurú y sus Miembros vs. Brasil (2018), y Comunidades indígenas lhaka honhat (Nuestra Tierra) vs. Argentina (2020).

7 Donnnelly, Jack, “The Relative Universality of Human Rights”, Human Rights Quarterly, vol. 29, núm. 2, 2007, pp. 281-306. 
Esto se hace más complejo cuando estas medidas consisten en reformas constitucionales o cambios legislativos profundos, en cuyos casos son esenciales mayorías políticas cualificadas para implementar las adaptaciones necesarias en el derecho interno. Como muestran Schönsteiner y Couso, este diagnóstico también es aplicable al SIDH. ${ }^{8}$

$\mathrm{Al} \mathrm{respecto,} \mathrm{está} \mathrm{descrito} \mathrm{en} \mathrm{la} \mathrm{literatura} \mathrm{sobre} \mathrm{interacciones} \mathrm{entre} \mathrm{derecho}$ internacional y derecho interno que el objetivo de producir cambios profundos en el plano nacional se consigue cabalmente sólo a partir de un complejo proceso de socialización, que excede lo meramente jurídico, pues también implica actividades de naturaleza política, de concienciación y de educación. ${ }^{9}$ Un segundo factor, relevante en este proceso, es el tiempo, siendo mayormente posible que la jurisprudencia internacional sea un factor que permita incoar cambios sustantivos sólo en el largo plazo, ${ }^{10}$ puesto que los principales agentes de dicho proceso serán, en definitiva, actores internos, como movimientos sociales, activistas de derechos humanos, medios de comunicación y partidos políticos, quienes deban llevar a cabo campañas de promoción a largo plazo para empujar mejores políticas en este sentido.

Ahora bien, con independencia de que la interacción entre derecho internacional y derecho interno nunca es sencilla, en materia de pueblos indígenas y tribales la situación se vuelve aún más compleja. En otras palabras, a esas dificultades de base se añaden otras que convierten esta tarea en un trabajo hercúleo. Tales dificultades son, al menos, de dos tipos: problemas de traducción cultural y de exclusión radical de los pueblos indígenas y tribales en el seno de los Estados nacionales. Cada una de estas circunstancias añade desafíos adicionales a la protección de sus derechos humanos. En ese sentido, la hipótesis que sometemos a discusión es que estas circunstancias determinan que toda la jurisprudencia sobre los pueblos indígenas esté

8 Schönsteiner, Judith y Couso, Javier, "La implementación de las decisiones de los órganos del Sistema Interamericano de Derechos Humanos en Chile: ensayo de un balance", Revista de Derecho Universidad Católica del Norte, año 22, núm. 2, 2015, pp. 315-355.

9 Risse, Thomas y Sikkink, Kathryn, “The Socializations of International Human Rights Norms into Domestic Practices: Introduction”, en Risse, Thomas et al. (eds.), The Power of Human Rights. International Norms and Domestic Change, Cambrige University Press, 1999, pp. $1-38$.

10 Cavallaro, James y Brewer, Stephanie, "Reevaluating Regional Human Rights Litigation in the Twenty-First Century: The Case of the Inter-American Court", The American Journal of International Law, vol. 102, 2008, pp. 768-827. 
marcada por una tensión entre lo ortodoxo y lo original y por un dilema entre lo ambicioso y lo realista, que condiciona los efectos que dicha jurisprudencia pueda llegar a producir en el derecho interno de los Estados signatarios.

Respecto de la primera de estas dicotomías, se origina en las implicancias culturales que, casi siempre, se encuentran presentes en estos casos. Los filósofos del derecho han discutido hondamente acerca de la universalidad de los derechos humanos y, justamente, este es un terreno que pone a prueba dicho aserto. Por ortodoxia se entiende una teoría estándar de los derechos humanos basada en el modelo liberal de derechos universales e individuales. Si bien se puede identificar como un caso paradigmático la teoría de los derechos humanos desarrollada por Rawls, en su libro The Law of the People,${ }^{11}$ un concepto de estas características es capaz de cubrir un amplio espectro de teorías, incluyendo algunas que incluso son sensibles a la diversidad cultural y a la protección de minorías como, por ejemplo, la conocida teoría de Will Kymlicka. ${ }^{12}$

En cuanto a lo segundo, en la gran mayoría de los casos las soluciones necesarias para reparar íntegramente la vulneración de los derechos de estos grupos requerirían intervenciones de gran calado, afectando a un número indeterminado de personas al interior de los Estados, puesto que buscan una trasformación de las relaciones de poder al interior de las respectivas sociedades. En otras palabras, una medida ambiciosa implicaría el diseño de políticas públicas a gran escala por parte de la Corte IDH, función que sólo podría quedar entregada a los órganos con legitimidad política al interior de los Estados.

Estas ideas permiten identificar las tensiones en la actividad de un tribunal como la Corte IDH, que, muchas veces, debe apostar por soluciones poco ortodoxas y/o que representan intervenciones profundas, aun sabiendo que dicha jurisprudencia difícilmente podrá ser cumplida íntegramente en el derecho interno del Estado condenado, al menos en el corto plazo. Por el contrario, en otras oportunidades el caso se resuelve en favor del pragmatismo y/o la ortodoxia, aunque la respuesta pierda cierta sintonía con la petición original de justicia.

11 Rawls, John, The Law of the People, Harvard University Press, 2001.

12 Kymlicka, Will, Multicultural Citizenship. A Liberal Theory of Minority Rights, Oxford University Press, 1995. 
En lo que sigue analizaremos cómo estas tensiones se hacen presentes en la jurisprudencia de la Corte IDH sobre pueblos indígenas y tribales, lo que permite explicar los aciertos, avances, retrocesos y contradicciones a lo largo de estos años.

\author{
III. DERECHOS HUMANOS \\ Y PROBLEMAS DE TRADUCCIÓN
}

En el contexto descrito, los tribunales internacionales tienen más probabilidades de ser eficaces cuando la jurisprudencia es capaz de ingresar como un elemento endógeno en el derecho interno. Al respecto, Hitters recurre a la metáfora de que la jurisprudencia internacional debe tener por objetivo "meterse" en la corriente sanguínea de los distintos países con la fuerza suficiente para lograr trastrocar sensiblemente ciertas normas locales, incluyendo a las de linaje constitucional. ${ }^{13}$ Por ello, los tribunales internacionales suelen prestar mayor atención a los casos que pueden generar un impacto de estas características, considerándolos como oportunidades para estimular un cambio más amplio o que produzca un mayor impacto. Ésta también es la visión que ha suscrito la Corte IDH en la generalidad de los casos que resuelve, intentando dialogar con los Estados miembros del SIDH y, al mismo tiempo, siendo extremadamente meticulosa en el desarrollo de su jurisprudencia.

Esta mirada se ha visto parcialmente desafiada en materia de pueblos indígenas y tribales, donde, a diferencia de otros ámbitos, ni ha sido tan fácil la formación de una doctrina coherente y consistente ni la jurisprudencia se ha infiltrado tan fácilmente en el derecho interno de los Estados. La razón pareciera ser su carácter poco ortodoxo, a pesar de que algunos autores han defendido que el enfoque progresista que ha adoptado la Corte IDH forma parte del "contenido inherente" de los derechos de la CADH. ${ }^{14} \mathrm{El}$ asunto es,

13 Hitters, Juan, “ ¿Son vinculantes los pronunciamientos de la Comisión y de la Corte Interamericana de Derechos Humanos? (Control de constitucionalidad y convencionalidad)", Revista Iberoamericana de Derecho Procesal Constitucional, núm. 10, 2008, pp. 131-156.

14 Estupiñan, Rosmerlin, "Pueblos indígenas y tribales: la construcción de contenidos culturales inherentes en la jurisprudencia interamericana de derechos humanos", Anuario Mexicano de Derecho Internacional, vol. XIV, 2014, pp. 581-616. 
por lo menos, polémico, pues existen otros autores que identifican en estos casos una teoría de los derechos colectivos y se preguntan si ello es compatible con la teoría clásica de los derechos humanos, más común en el derecho interno de los Estado signatarios. ${ }^{15}$ Esta pregunta se vuelve imperativa incluso para la propia Corte IDH, que ha enfatizado, en la OC 22/16, que los derechos de la CADH son, eminentemente, derechos de los individuos y no de los colectivos, lo que hace necesario explicar el fundamento de la excepción para estos casos.

Como es sabido, los derechos humanos se han expresado tradicionalmente en el lenguaje de los derechos subjetivos individuales. En términos históricos, la genealogía del concepto de derechos humanos se remonta a la Edad Media, momento en que se vincula la idea de derecho subjetivo a la propiedad privada. ${ }^{16}$ Posteriormente, durante la Modernidad, esa misma noción se utilizó en la formulación del concepto de derechos humanos.

Al respecto, Eusebio Fernández ${ }^{17}$ afirma que en el paso del derecho natural objetivo (derecho como norma) al derecho natural subjetivo (derecho como facultad inherente al sujeto) se encuentra la invención del concepto de derechos naturales subjetivos. Esta idea la encontramos, por ejemplo, en Grocio, donde ius se ha convertido en el concepto de derecho subjetivo; es decir, en la facultad o cualidad moral de la persona para poseer o hacer algo justamente. ${ }^{18}$ De este modo, el lenguaje de los derechos ha sido creado y moldeado en función de la protección de la propiedad privada desde los albores de la Modernidad, empresa que ha tomado mayor fuerza con el desarrollo de la economía capitalista.

Si lo anterior es correcto, el corolario será una necesaria tensión en el mismo concepto de derechos humanos de los pueblos indígenas y tribales, puesto que, justamente, esta clase de reivindicaciones han surgido como resistencia al modelo social y económico occidental, buscando preservar la autonomía res-

15 Sauca, José María y Wences, Isabel, "Derechos colectivos (en la doctrina de la Corte Interamericana de Derechos Humanos)”, EUNOMÍA. Revista en Cultura de la Legalidad, 2015, pp. 195-204.

16 Guzmán, Alejandro, "Historia de la denominación del derecho-facultad como «subjetivo»", Revista de Estudios Histórico-Jurídicos, núm. 25, 2003, pp. 407-443.

17 Fernández, Eusebio, “El problema del fundamento de los derechos humanos”, Anuario de Derechos Humanos, 1982, p. 84.

18 Blanco, Jesús, "Las concepciones del ius naturale o los fundamentos de la política en Grocio, Hobbes y Espinoza”, Papeles de Filosofía, vol. 22, núm. 1, 2003, pp. 11-131. 
pecto de la apropiación de sus formas culturales por el mercado. ${ }^{19}$ Así, el uso del discurso de los derechos humanos parece ser, en muchos casos, meramente estratégico, pues resulta ser una de las pocas herramientas que ha demostrado cierta funcionalidad en la lucha por la emancipación de dichos pueblos. Sin embargo, este discurso está conformado por unas categorías intelectuales y por una nomenclatura ajenas a las culturas originarias de América.

Ello produce una serie de disfunciones; por ejemplo, un eventual desajuste entre la verdadera demanda y su traducción a la nomenclatura de la $\mathrm{CADH}$, siendo plausible sostener que no siempre en los tratados internacionales existe una respuesta exacta para las reivindicaciones de los pueblos indígenas. De esta forma, si la Corte IDH persigue un cumplimiento eficaz de las sentencias, debería ser consciente de que la consecuencia más probable será una suerte de "efecto de pérdida de fidelidad de la demanda". Por el contrario, si el objetivo principal es la fidelidad, las posibilidades de que sus sentencias produzcan efectos realmente transformadores se reducirán de manera importante.

Esta circunstancia no es trivial y algunos autores han asumido la infructuosidad de dicha empresa. Por ejemplo, De Sousa Santos ha señalado que únicamente si se adopta una política de derechos humanos radicalmente distinta de la hegemónica liberal, y solamente si tal política se concibe como parte de una más amplia constelación de luchas y discursos de resistencia y emancipación, se puede llegar a dar solución a este problema. ${ }^{20}$ En este sentido, se puede afirmar que la Corte IDH, en este tipo de asuntos, enfrenta dificultades similares a las de un traductor que debe solucionar una laguna léxica. Esto significa que sería necesario recurrir a herramientas parecidas a las que hacen posible la incorporación de un término extranjero, que carece de un equivalente en la lengua de destino. Llamaremos a este fenómeno la paradoja de la traducción: a medida que se es más fiel al discurso original, la traducción es menos comprensible para las estructuras jurídicas del derecho interno y viceversa.

Esta tensión entre lo ortodoxo y lo original ha estado presente en toda la jurisprudencia de la Corte IDH sobre pueblos indígenas y tribales. Un

19 Witheley, Peter, "Do «Language Rights» Serve Indigenous Interests? Some Hopi and Other Queries”, American Anthropologist, New Series, vol. 105, núm. 4, 2003, pp. 712-722.

20 Sousa Santos, Boaventura de, Descolonizar el saber, reinventar el poder, Santiago de Chile, LOM Editores, 2013, p. 65. 
Esta revista forma parte del acervo de la Biblioteca Jurídica Virtual del Instituto de Investigaciones Jurídicas de la UNAM

buen ejemplo de este problema lo encontramos en la jurisprudencia que se ha generado en torno al artículo 21 de la $\mathrm{CADH}$, aunque también se puede hacer referencia a un caso sobre libertad de expresión y criminalización de la protesta.

\section{1. ¿Existe la propiedad comunal indígena?}

Esta materia representa un porcentaje importante de las sentencias sobre pueblos indígenas y tribales. ${ }^{21}$ La Corte IDH, desde el caso Awas Tingni vs. Nicaragua, ha intentado resolver una de las demandas más transversales en las sociedades americanas: la recuperación de tierras. Como es de conocimiento público, tanto los colonizadores europeos como los Estados nacionales despojaron violentamente de sus territorios a los pueblos indígenas y tribales. En la actualidad, éstos han enarbolado la demanda de la restitución del espacio geográfico en el que habitaron sus ancestros. En todos los casos en que se ha invocado el derecho a la propiedad privada del artículo 21 de la $\mathrm{CADH}$, la Corte IDH ha fallado en contra del Estado. ${ }^{22}$ No obstante, como se podrá ver a continuación, este es un típico caso de laguna léxica.

Es importante señalar que han sido también las propias víctimas — no sólo la Comisión Interamericana de Derechos Humanos - quienes han invocado el artículo 21 de la CADH, lo que demuestra que los intentos de traducción se producen en ambos sentidos, dado que el concepto de propiedad privada era desconocido para los pueblos precolombinos. Lamentablemente, no existen estudios en el marco del SIDH que expliquen

21 Awas Tingni vs. Nicaragua (2001); Moiwana vs. Suriname (2005); Yake Axa vs. Paraguay (2005); Sawhoyamaxa vs. Paraguay (2006); Saramaka vs. Suriname (2007); Xákmok Kásek vs. Paraguay (2010); Sarayaku vs. Ecuador (2012); Madungandí y Emberá de Bayano vs. Panamá (2014); Pueblos Kaliña y Lokono vs. Surinam (2015); Comunidad Garifuna de Punta Piedra y sus Miembros vs. Honduras (2015); Comunidad Garifuna Triunfo de la Cruz y sus Miembros vs. Honduras (2015); Pueblo Indígena Xucurú y sus Miembros vs. Brasil (2018), y Comunidades Indígenas lhaka honhat (Nuestra Tierra) vs. Argentina (2020).

22 Artículo 21. Derecho a la propiedad privada: "1. Toda persona tiene derecho al uso y goce de sus bienes. La ley puede subordinar tal uso y goce al interés social. 2. Ninguna persona puede ser privada de sus bienes, excepto mediante el pago de indemnización justa, por razones de utilidad pública o de interés social y en los casos y según las formas establecidas por la ley. 3. Tanto la usura como cualquier otra forma de explotación del hombre por el hombre, deben ser prohibidas por la ley". 
esta conducta, aunque sí pueden mencionarse trabajos situados en otros contextos. Por ejemplo, Brian Thom sugiere que en Canadá los pueblos originarios han abrazado el discurso de los derechos humanos por razones puramente estratégicas, en una suerte de consenso por superposición. ${ }^{23}$ Otros autores plantean que dicha relación se produce no sin un costo para los usuarios. Por decir, en el caso de comunidades Nuu-chah-nulth, Mack argumenta que, al adoptar el reconocimiento de títulos y las leyes de tierras indígenas, éstas terminaron internalizando actitudes y procesos coloniales. ${ }^{24}$ En Australia, Elizabeth Povinelli ha mostrado cómo las categorías y las lógicas estatales terminan perpetuando las ideas liberales, poniendo en peligro las formas culturales propias de las poblaciones originarias. ${ }^{25}$

Como sea, a medida que esta línea jurisprudencial va evolucionando, la tensión se va haciendo evidente. En Sumo Awas Tingni, la comunidad denunció al Estado por no haber tomado medidas que aseguraran los derechos de propiedad sobre sus tierras ancestrales, pues éste otorgó una concesión forestal sobre aquellas sin el consentimiento de la comunidad. Esta última solicitó internamente revocar la concesión y delimitar las tierras, no obteniendo resultados positivos ante los tribunales nicaragüenses. En este caso la Corte IDH intenta, por primera vez, dotar al concepto de propiedad privada de un contenido eminentemente cultural, acuñando la noción de propiedad comunal indígena a su juicio, diferente de la idea clásica de copropiedad reconocida en todos los códigos civiles de Latinoamérica.

En este caso la Corte IDH se enfrenta por primera vez al dilema, quedando claro en la sentencia lo complejo de fundamentar jurídicamente un tipo de propiedad distinto del derecho real de dominio, entendido este último como el conjunto de poderes exclusivos sobre una cosa específica y delimitada. Para ello recurre, en primer lugar, al originalismo interpretativo, señalando que, durante los trabajos preparatorios de la CADH, se reemplazó la frase "[t]oda persona tiene el derecho a la propiedad privada", por "[t]oda persona tiene derecho al uso y goce de sus bienes" (parr. 145),

23 Thom, Brian, "Reframing Indigenous Territories: Private Property, Human Rights and Overlapping Claims", American Indian Culture and Research Journal, vol. 38, núm. 4, 2014, pp. 3-28.

24 Povinelli, Elizabeth, The Cunning of Recognition, Durham, Duke University Press, 2002.

25 Mack, Johnny, "Hoquotist: Reorienting through Storied Practice”, en Lessard, Hester et al. (eds.), Narratives of Contact and Arrival in Constituting Political Community, Vancouver, University of British Columbia Press, 2011, p. 298. 
lo que justificaría que el artículo 21 de la CADH reconozca formas alternativas de vinculación entre personas y bienes. Esta línea argumentativa desaparecerá en sentencias posteriores.

Paralelamente, se intenta un segundo camino, acuñándose el concepto de propiedad comunal. En palabras de la propia Corte IDH, esta sería un tipo de propiedad que se caracteriza por la existencia de una especial vinculación de carácter espiritual entre la comunidad y su territorio ancestral, y que resulta de vital importancia para su supervivencia. Sin embargo, la sentencia no explica cómo surge este vínculo espiritual ni por qué es jurídicamente relevante. Lo inextricable del asunto se demuestra en la parte dispositiva, pues a pesar de que la idea de propiedad comunal aparece casi como un letmotiv en los fundamentos jurídicos, la ratio decidenci vuelve a la lógica clásica de la propiedad. En efecto, todo el énfasis está puesto en la delimitación y regularización de las tierras indígenas y en que los miembros del pueblo Sumo puedan regularizar, de la forma más simple posible, sus títulos, demarcando, saneando y registrando sus tierras. No obstante, el verdadero problema no era ese, sino que consistía, en parte importante, en actividades productivas que se llevaban a cabo fuera de las tierras Awas Tingi, pero que impactan en el ecosistema de toda la costa atlántica nicaragüense.

En este primer intento el voto de mayoría se decantó por la ortodoxia, a pesar de que la respuesta pierde fidelidad con respecto a la demanda original. Esta tensión al interior de la Corte IDH se aprecia más claramente en los votos particulares (todos concurrentes). En uno de ellos se recalca que la comunidad posee "una tradición contraria a la privatización y a la comercialización y venta (o alquiler) de los recursos naturales (y su explotación)" ${ }^{26}$ Por lo mismo, la cuestión desborda de un tratamiento como un asunto meramente patrimonial. En efecto, este voto particular considera necesario relevar que ha quedado acreditado en el proceso, que desprovistos de sus tierras, la comunidad se vería privada de practicar, conservar y revitalizar las costumbres culturales que dan sentido a su propia existencia y, por tanto, disociar estos dos elementos significa la negación de la existencia política de la comunidad. En otro de los votos particulares se observa una postura aún más radical, que insiste en la contradicción en que incurre el voto de mayoría, expresando que, si bien en el lenguaje de la

26 Voto razonado de los jueces Cançado Trindade, M. Pacheco Gómez y Abreu Burelli. 
Convención la demanda del pueblo Sumo se inscribe en el marco del derecho de propiedad, ella "desborda con creces este concepto tradicional en el que prima la relación individual”. ${ }^{27}$

En Moiwana vs. Surinam la Corte IDH vuelve a enfrentarse a un problema similar, aunque en esta oportunidad se muestra más conservadora. El caso trata sobre las reivindicaciones territoriales de la comunidad Ndjuka de Moiwana, objeto de un desplazamiento forzado que deja como consecuencia decenas de muertos. El pueblo Ndjuka tiene rituales específicos que se deben seguir después de la muerte de una persona, cuya inobservancia representa una transgresión moral profunda. Una de las principales fuentes de sufrimiento para la comunidad es desconocer el paradero de los fallecidos y no poder enterrarlos en el lugar que fuera su hogar en vida. En la prueba rendida, todas las declaraciones de los miembros de la comunidad concordaron en la necesidad de regresar urgentemente a sus tierras para restaurar sus vidas, habiendo sido completamente ignorados por el Estado.

Ante situaciones de despojo territorial, el enfoque de derecho civil clásico establece que, una vez que la comunidad ha sido desplazada y la propiedad es adquirida por terceros por prescripción, se pierde cualquier derecho sobre las tierras. En esos casos, la comunidad podría únicamente demandar al Estado una indemnización de perjuicios. Así fue, justamente, como la Corte IDH resolvió el caso Moiwana.

En Yakye Axa vs. Paraguay la tensión entre la ortodoxia y la originalidad vuelve a aparecer. Por una parte, la Corte IDH intenta nuevamente argumentar en favor de una propiedad indígena de naturaleza extrapatrimonial, reinterpretando el término bienes del artículo 21 de la CADH, al señalar que éstos no son sólo las cosas apropiables, sino también "cualquier otro objeto inmaterial susceptible de tener un valor", destacando que no necesariamente se debe identificar al término valor con un contenido pecuniario o apreciable en dinero. La pregunta que surge entonces es cómo se podría proteger, a través del derecho de propiedad, entidades no susceptibles de apropiación o de estimación pecuniaria. La Corte IDH no se detiene en responder a esta interrogante. Quizá ello explica por qué esta doctrina tampoco vuelve a ser invocada posteriormente.

Pero Yakye Axa también inaugura un camino paralelo más convencional, que a la postre se convertirá en jurisprudencia permanente: plantear el

27 Voto razonado del juez H. Salgado Pesantes. 
asunto como un conflicto entre dos distintos derechos de propiedad. En efecto, en esta sentencia se esbozan por primera vez criterios para solucionar conflictos cuando la propiedad comunal indígena y la propiedad privada clásica entran en contradicción. Aunque para romper el empate la Corte IDH otorga mayor peso a la primera, ligándola con el derecho colectivo a la supervivencia como pueblo organizado. En sus propias palabras: "[a]l desconocerse el derecho ancestral de los miembros de las comunidades indígenas sobre sus territorios, se podría estar afectando otros derechos básicos, como el derecho a la identidad cultural y la supervivencia misma de las comunidades indígenas y sus miembros" (párrs. 147 y 148). Por el contrario, las restricciones a la propiedad privada de particulares no supondrían este problema, por lo que estarían autorizadas por la $\mathrm{CADH}$, siempre que éstas sean proporcionadas. Así las cosas, la expropiación en estos casos no vulneraría la $\mathrm{CADH}$, si es que los perjudicados son resarcidos con el pago de una justa indemnización, conforme al artículo 21.2 de la CADH.

Si bien esta solución logra reducir parcialmente la laguna léxica, no la elimina. Por otra parte, esta interpretación tampoco deja de ser audaz y ha sido criticada desde otra perspectiva: representa una visión en la que la Corte IDH interpreta extensivamente el contenido y los contornos de los tratados, incluso por sobre el carácter convencional del derecho internacional; por ejemplo, invocando de manera subrepticia otros derechos que no están reconocidos expresamente por la CADH. Esta estrategia de los derechos implícitos, que se ha utilizado también en otras materias complejas, parece prestar poca atención al consenso de los Estados, el cual resulta un elemento fundamental en el derecho internacional. ${ }^{28}$ Se volverá sobre este tema más adelante.

Para terminar, en Xákmok Kásek vs. Paraguay la Corte IDH fija oficialmente su doctrina actual, insistiendo en la relevancia cultural de la propiedad comunal indígena, pero a la hora de fallar siempre termina traduciendo dicho concepto a las categorías clásicas del derecho civil. Así las cosas, propiedad comunal indígena significa lo siguiente: 1) la posesión tradicional de los indígenas es equivalente a un título de dominio otorgado por el Estado; 2) la posesión tradicional otorga el derecho a exigir el reconocimiento oficial de propiedad y su registro; 3) el Estado debe delimitar, demarcar y otorgar título colectivo de dichas tierras; 4) las comunidades indígenas que, por

28 Neuman, Gerald, "Import, Export, and Regional Consent in the Inter-American Court of Human Rights”, European Journal of International Law, vol. 19, núm. 1, 2008, pp. 101-123. 
causas ajenas a su voluntad, hayan perdido la posesión de sus tierras tradicionales mantienen sus derechos sobre las mismas, salvo que dichas tierras hayan sido legítimamente adquiridas por terceros de buena fe, y 5) en este último caso las comunidades tienen el derecho de recuperarlas o a obtener otras tierras de igual extensión y calidad (párrs. 85 y ss.).

\section{Libertad de expresión y pueblos indígenas}

En el contexto de represión sistemática que han ejercido los Estado nacionales, es probable que surjan formas de resistencia que conlleven acciones de fuerza. Los casos más conocidos internacionalmente son los de Chiapas, en México, y el conflicto territorial entre el Estado chileno y el pueblo mapuche. Este último fue objeto de una sentencia de alta significación para el SIDH en 2012. Al respecto, la sentencia Norín Catrimán y otros vs. Chile posee varias aristas interesantes, aunque por ahora interesa el capítulo relacionado con la libertad de expresión, donde el Estado chileno resultó condenado por vulnerar el artículo 13 de la $\mathrm{CADH}$.

En síntesis: el asunto se refiere a las sanciones impuestas a ocho dirigentes mapuche que habían sido condenados penalmente bajo la figura de incendio terrorista. El delito en cuestión imponía, además de la pena de privativa de libertad, una pena accesoria de inhabilitación para el ejercicio de cargos y oficios públicos, que es la prevista en el artículo 9o. de la Constitución Política de Chile, que señala lo siguiente:

Los responsables de estos delitos quedarán inhabilitados por el plazo de quince años para ejercer funciones o cargos públicos, sean o no de elección popular, o de rector o director de establecimiento de educación, o para ejercer en ellos funciones de enseñanza; para explotar un medio de comunicación social o ser director o administrador del mismo, o para desempeñar en él funciones relacionadas con la emisión o difusión de opiniones o informaciones; ni podrán ser dirigentes de organizaciones políticas o relacionadas con la educación o de carácter vecinal, profesional, empresarial, sindical, estudiantil o gremial en general, durante dicho plazo.

La Corte IDH estimó que Chile vulneró la libertad de expresión de los denunciantes (únicamente) por las siguientes razones: a) por haber sido 
impuesta la pena fundándose en sentencias condenatorias que aplicaron una ley penal violatoria del principio de legalidad; $b$ ) por vulneración de garantías procesales, y c) por vulnerar el principio de la proporcionalidad de la pena. Si bien es cierto que la Corte IDH sí menciona la dimensión colectiva en su razonamiento, ésta desaparece en la parte dispositiva, adoptándose un enfoque exclusivamente individual. Este caso también se puede explicar como un problema de traducción; es decir, como una laguna léxica, puesto que no resulta comprensible desde las categorías culturales propias del pueblo mapuche. No obstante, si la Corte hubiera sido fiel a la cosmovisión mapuche, la sentencia habría sido difícilmente comprensible en el lenguaje de una teoría estándar de los derechos humanos.

Todo aquel que conoce la cultura mapuche sabe que dentro de su cosmovisión el individuo se diluye dentro del colectivo, por lo que para ellos la conducta del Estado chileno representa una ofensa contra toda comunidad, no sólo en contra de ocho de sus miembros. ${ }^{29}$ En este contexto, se puede recordar que incluso la teoría de los derechos humanos ofrecería una mejor lectura para entender la libertad de expresión para este caso, en la teoría de la dimensión institucional de la libertad de expresión de Owen Fiss. ${ }^{30}$ Esta tesis concibe a la libertad de expresión no simplemente como una protección de la autonomía personal, sino, más bien, como una garantía de la formación de una opinión crítica y pluralista en la comunidad, aspecto esencial en cualquier democracia. ${ }^{31}$

Aunque esta segunda perspectiva se aproximaría mejor a la comprensión que podría tener un mapuche de los hechos, aun así seguiría sin ser una traducción fluida. En algún sentido, la Corte IDH captura parcialmente la especificidad cultural cuando estima que dichas personas, en tanto autoridades tradicionales del pueblo mapuche, les incumbe un papel determinante en la comunicación de los intereses y en la dirección política, espiritual y social de sus respectivas comunidades (párr. 375). Por esta razón, argumenta que la imposición de dicha pena limita severamente la posibilidad de participar en la difusión de opiniones, ideas e información de

29 Sánchez Curihuentro, Juan, "El Az Mapu o sistema jurídico mapuche”, Revista CREA, núm. 2, 2001, p. 36.

30 Fiss, Owen, "Libertad de expresión y estructura social”, en Ávila, Maria et al. (ed.), Libertad de expresión: debate, alcances y nueva agenda, Quito, Unesco, 2011, p. 68.

31 Ibidem, p. 82. 
los ocho dirigentes, pero también de las comunidades a las que representan. Sin embargo, como ya se señaló, la parte dispositiva de la sentencia soslaya completamente la dimensión colectiva y se refiere únicamente a las ocho autoridades ya mencionadas.

Para el pueblo mapuche, atentar contra un werken (mensajero o portavoz) o un lonko (cabeza o jefe) significa una afrenta contra el colectivo, y los efectos que ello produce podrían traducirse, en esta cultura, como una declaración de guerra (hueicha). Ello porque estas autoridades son fundamentales para que la comunidad pueda existir, interactuar con otras comunidades o con las autoridades chilenas. En otras palabras, se trata de un atentado político en contra de la comunidad en sí misma.

Desde la perspectiva occidental, bien podría sostenerse que se trata de un acto de expulsión de la comunidad política dentro del Estado chileno, pues como afirma Velasco, este problema se refiere a la delimitación del demos constitutivo en un determinado espacio geográfico. ${ }^{32}$ La criminalización de las autoridades tradicionales es, en efecto, un acto de desarticulación del pueblo mapuche en particular, y general, un ataque en contra de las culturas indígenas, con sus propias identidades, tradiciones, costumbres, organización social y cosmovisión. No se debe perder de vista que la desarticulación política y cultural de los pueblos originarios ha sido una política pública practicada durante siglos para "integrar" o "asimilar" a los indígenas. ${ }^{33}$

Si se pretende cambiar la realidad antes descrita, probablemente se deban adoptar estrategias que excedan el mero uso del lenguaje de los derechos humanos subjetivos individuales. ${ }^{34}$ Esto no quiere decir que los derechos humanos no sean parte de la estrategia, pero dado que éstos no siempre son capaces de captar la verdadera esencia de las demandas de justicia que emanan de las comunidades indígenas y tribales, es necesario desarrollar políticas públicas que sean sensibles frente a las diferencias culturales. Un buen ejemplo

32 Velasco, Juan, "La noción republicana de ciudadanía y la diversidad cultural”, Isegoría, núm. 33, 2006, pp. 191-206.

33 Stavenhagen, Rodolfo, "Identidad indígena y multiculturalidad en América latina", Araucaria. Revista Iberoamericana de Filosofía, Política y Humanidades, vol. 4, núm. 7, 2002, p. 13.

34 Como muestra de que el problema excede a las ocho víctimas del caso Norín Catrimán, en la opinión chilena ha causado gran impacto el caso del lonko Alberto Curamil, también condenado penalmente, quien, en 2019, fue galardonado con el Premio Goldman, sin tener la posibilidad de viajar a San Francisco a recibirlo. Curamil se destacó por organizar una campaña para detener la construcción de dos proyectos hidroeléctricos y un río sagrado. 
de que el derecho internacional puede ser útil en este aspecto es el artículo 16 de la Declaración sobre los Derechos de los Pueblos Indígenas de la ONU, que dispone que éstos tienen derecho a establecer sus propios medios de información, en sus propios idiomas, y a acceder a todos los demás medios de información no indígenas sin discriminación.

Una idea similar plantea La Rue,$^{35}$ quien ha planteado que los medios de comunicación social deben ser representativos y diversos en cuanto a su personal, y, además, que en su cobertura generen un ambiente de respeto a la diversidad cultural y multiculturalidad. Según este autor, los medios, aparte, deben promover y proteger los idiomas de las minorías y los pueblos indígenas, lo que incluye el derecho a expresarse en su propio idioma, así como reproducir su cultura y tradiciones de manera privada y pública.

Sin embargo, medidas de estas características parecen aún tener un papel meramente testimonial dentro del derecho internacional público, en su estadio actual de desarrollo y, en cualquier caso, para que se hagan realidad, requerirían de políticas públicas integrales que integren acciones de concientización y educación del carácter multicultural de las sociedades americanas.

\section{DERECHOS HUMANOS, POBREZA, DESIGUALDAD Y EXCLUSIÓN RADICAL}

Una segunda dificultad que frecuentemente enfrentan las sentencias de la Corte IDH sobre pueblos indígenas y tribales se relaciona con el hecho de que éstas deben lidiar con contextos de pobreza, desigualdad y exclusión radical. Como sabemos, las poblaciones indígenas y tribales, por regla general, se encuentran en una situación de vulneración estructural de derechos básicos, con importantes niveles de carencia en el acceso a bienes y servicios elementales. A esto hay que añadir que han sido sometidos al expolio de sus recursos naturales, negándoseles la capacidad de decidir sobre éstos, lo que ha empeorado exponencialmente su situación. Lo anterior configura un panorama que los sitúa entre los grupos más pobres del

35 La Rue, Frank, "Libertad de expresión de los pueblos indígenas, minorías y grupos vulnerables”, en Ávila, María et al. (eds.), Libertad de expresión: debate, alcances y nueva agenda, Quito, Unesco, 2011, pp. 243-252. 
continente. El principal problema que aquí se presenta es que la exclusión social, económica y política, derivada de los niveles extremos y persistentes de desigualdad, termina por aniquilar la imparcialidad legal y provoca la invisibilidad de los sumamente pobres. ${ }^{36}$

Para enfrentar situaciones así, la Corte IDH también ha debido concebir sus decisiones como acciones que tienen por propósito intervenir en los sistemas nacionales, a veces con bastante profundidad. En definitiva, en este tipo de casos se presenta un dilema estratégico de características similares al anterior: o la Corte IDH puede ser ambiciosa, pero correr el riesgo de ser poco exitosa en generar sinergias con el derecho interno, o puede plantearse objetivos más modestos, que constituirán avances menores pero con mayores posibilidades de resultar fructíferos. Frente a esta disyuntiva no siempre será fácil determinar lo óptimo entre estas dos variables en juego.

La estrategia que ha utilizado la Corte IDH ha sido la interpretación extensiva de los derechos reconocidos en la CADH, utilizando técnicas como el ius cogens o el diálogo con otras jurisdicciones externas al SIDH. También cabe en esta categoría toda la jurisprudencia sobre medidas reparatorias, aspecto en el que la Corte IDH aparece como uno de los tribunales más creativos del mundo. ${ }^{37}$ Adicionalmente, al problema económico de la escasez las decisiones de la Corte IDH, en este tipo de situaciones, enfrentan otro problema, relativo a su legitimidad para intervenir en el diseño de políticas públicas. Por lo general estas intervenciones inciden sobre ámbitos en los que internamente existe un profundo disenso, por ejemplo: decisiones estratégicas sobre el uso y explotación de recursos naturales, la existencia y alcance de derechos sociales, etcétera. Por este motivo los Estados tienden a ser minimalistas en la suscripción de compromisos internacionales en estas materias, lo que explica la apuesta por la interpretación extensiva que ha realizado la Corte IDH.

La estrategia ha sido motivo de críticas, cuestionándose su legitimidad democrática para obrar en tal sentido, sobre todo en lo que concierne a establecer estándares que imponen obligaciones a los Estados no expresa-

36 Cimadamore, Alberto et al., Pueblos indígenas y pobreza. Enfoques multidisciplinarios, Buenos Aires, Clacso, 2006.

37 Schönsteiner, Judith, "Dissuasive Measures and the Society as a Whole: A Working Theory of Reparations in the Inter-American Court of Human Rights", American University International Law Review, vol. 23, 2007, pp. 127-164. 
mente asumidas por los tratados del SIDH. ${ }^{38} \mathrm{Al}$ respecto, se ha sostenido que en el SIDH podría tener cabida una solución similar a la doctrina del margen de apreciación, utilizada por el Tribunal Europeo de Derechos Humanos para solventar la falta de consenso en determinadas materias, reconociendo a los Estados cierta latitud a la hora de interpretar el Convenio Europeo de Derechos Humanos. ${ }^{39}$ Justamente, esta doctrina ha surgido como un intento de impulsar un equilibrio entre las visiones nacionales de los derechos humanos y la aplicación uniforme de los valores del Convenio Europeo, lo que para estos autores deja en evidencia el carácter subsidiario del derecho internacional. ${ }^{40}$

Pero la Corte IDH también ha sido criticada desde la perspectiva contraria; es decir, porque sus intervenciones carecen de la relevancia y asertividad necesarias para provocar cambios reales. En este sentido, Thomas Antkowiak ha señalado que, a pesar de que ésta normalmente utiliza términos como restitutio in integrum u ordena medidas que se dirigen explícitamente a la "sociedad en su conjunto", al examinarse las reparaciones decretadas, están lejos de acercarse al óptimo. ${ }^{41}$ En efecto, este autor puntualiza que, muchas veces, la Corte IDH debe decidir entre la dimensión individual o la dimensión colectiva del asunto, una en perjuicio de la otra, cuando lo ideal sería considerar los dos aspectos conjuntamente. De todas formas, reconoce que la Corte IDH ha sido pionera en abordar este tipo de casos, y que por su complejidad la restauración completa de las víctimas a menudo está fuera de alcance, especialmente en casos de grupos grandes.

38 Paul, Álvaro, "La Corte Interamericana in vitro: comentarios sobre su proceso de toma de decisiones a propósito del caso Artavia”, Derecho Público Iberoamericano, núm. 2, 2013, pp. 303-345; Neuman, Gerald, op. cit.

39 Contreras, Pablo, "Control de Convencionalidad, deferencia internacional y discreción nacional en la jurisprudencia de la Corte Interamericana de Derechos Humanos”, Ius et Praxis, vol. 20, núm. 2, 2014, pp. 235-274; Núñez, Manuel, "Sobre la doctrina del margen de apreciación nacional. La experiencia latinoamericana confrontada y el thelos constitucional de una técnica de adjudicación del derecho internacional de los derechos humanos", en Acosta, Paola y Núñez, Manuel (coords.), El margen de apreciación en el Sistema Interamericano de Derechos Humanos: proyecciones regionales y nacionales, México, UNAM, Instituto de Investigaciones Jurídicas, 2012, pp. 3-49.

40 Arai-Takahashi, Yutaka, The Margin of Appreciation Doctrine and the Principle of Proportionality in the Jurisprudence of the ECHR, Amberes, Intersentia, 2002, p. 3.

41 Antkowiak, Thomas, “A Dark Side of Virtue: The Inter-American Court and Reparations for Indigenous Peoples”, Duke Journal of Comparative \&International Law, vol. 25, 2014, pp. 1-80. 
Si bien estas críticas poseen un carácter más general, que excede los asuntos sobre pueblos indígenas, es en dicho ámbito donde se pueden encontrar claros ejemplos donde se manifiesta esta tensión. A continuación, se revisará un par de ellos.

\section{El derecho a la consulta previa}

Los casos sobre consulta previa plantean la pregunta acerca de cuál es el papel de las comunidades para decidir sobre los recursos naturales ubicados en su territorio y que buscan ser explotados económicamente por el Estado o por particulares con autorización del Estado. Como dato importante, se debe mencionar que el derecho a la consulta no está regulado en ninguna norma del SIDH, sino que está consagrado en el Convenio 169 de la Organización Internacional del Trabajo (OIT), por lo que, en principio, la Corte IDH no podría invocar dicho tratado.

La jurisprudencia sobre el derecho a la consulta previa se inicia en Saramaka vs. Surinam y alcanza su madurez en Sarayaku vs. Ecuador. En Saramaka, la denuncia se origina en la emisión de una serie de concesiones madereras y mineras para la explotación y extracción de recursos naturales que se encuentran dentro del territorio comunitario. En esta sentencia la Corte IDH adopta una estrategia bastante audaz: decide aplicar una solución incluso más exigente para el Estado que la establecida por el propio Convenio 169, el cual, por cierto, Surinam ni siquiera había ratificado. El argumento fue que exigir el consentimiento de las comunidades es una obligación de ius cogens, lo que quiere decir que es una norma generalmente aceptada por la comunidad internacional, sobre la que existe consenso en su obligatoriedad.

En específico, la sentencia declara que los artículos 1.1 y 26 de la CADH deben ser interpretados a fin de garantizar que las restricciones impuestas a la comunidad, a causa de concesiones otorgadas en su territorio, no impliquen una denegación de su subsistencia como pueblo tribal. Con este propósito, el Estado debe cumplir con las siguientes garantías: primero, debe asegurar la participación efectiva del pueblo saramaka, conforme con sus costumbres y tradiciones, en toda actividad económica que se ejecute dentro de su territorio; segundo, se debe garantizar que el pueblo saramaka se beneficie razonablemente de toda actividad de estas característi- 
cas, y tercero, se debe garantizar que no se otorgará ninguna concesión dentro del territorio saramaka, a menos que entidades independientes y técnicamente capaces, bajo la supervisión del Estado, realicen un estudio previo de impacto social y ambiental. Estas obligaciones, en teoría, serían suficientes para satisfacer el estándar del Convenio 169, pero la sentencia de marras va incluso más lejos del aseguramiento de la participación efectiva, pues añade que se requiere el consentimiento "libre, informado y previo" de las comunidades involucradas. Esta exigencia es alta, teniendo en cuenta que el Convenio 169 rechazó la obligación de buscar el consentimiento de los pueblos indígenas para la aprobación de las medidas que los pudieran afectar, reemplazándose ese concepto por la noción de consulta en su artículo 6o. ${ }^{42}$

En Sarayaku vs. Ecuador la Corte IDH vuelve a configurar su doctrina, retrocediendo respecto de la tesis defendida en Saramaka. Una posible explicación podría ser que Surinam, hasta la fecha, no ha cumplido con las medidas reparatorias decretadas en la sentencia. ${ }^{43}$ Por el contrario, a pesar de que el caso contra Ecuador es posterior en cinco años, el Estado ha dado cumplimiento de forma importante a las obligaciones establecidas por la sentencia. Además, otro dato importante es que Ecuador sí había ratificado el Convenio 169 de la OIT, por lo que es un antecedente que hace presumir la colaboración del Estado, lo que aumenta las posibilidades de cumplimiento.

Concretamente, en Sarayaku la Corte IDH resuelve que el Estado, para autorizar planes de desarrollo o inversión dentro del territorio comunitario, "tiene el deber de consultar, activamente y de manera informada, con dicha comunidad, según sus costumbres y tradiciones, en el marco de una comunicación constante entre las partes" (párr. 177). Añadiéndose que las consultas tienen que realizarse de buena fe, por medio de procedimientos culturalmente adecuados, y que deben tener como fin llegar a un acuerdo. Asimismo, se señala que se debe consultar en las primeras etapas del plan de desarrollo o inversión y no sólo cuando surja la necesidad de obtener la aprobación de la comunidad. En definitiva, sería el incumplimiento de la obligación de la realización de la consulta, sin observar sus características esenciales, lo que

42 Mereminskaya, Elina, "El Convenio 169 de la OIT sobre Pueblos Indígenas y Tribales. Derecho Internacional y experiencias comparadas”, Estudios Públicos, núm. 121, 2011, p. 222.

43 Resolución de cumplimiento de sentencia, 26 de septiembre de 2018, caso del Pueblo Saramaka vs. Surinam. 
compromete la responsabilidad internacional de los Estados, y no el consentimiento, tal como se exigió en la primera sentencia.

2. El derecho a la vida digna de los pueblos indígenas

Otro ejemplo de este dilema se encuentra en el reconocimiento de derechos sociales, a través de una relectura de derechos civiles. La Corte IDH, en su primera década, entendió el derecho a la vida como el derecho a no ser privado de la vida arbitrariamente, ya sea por agentes estatales o por particulares con tolerancia del Estado. Sin embargo, ya a finales de la década de 1990, se comenzó a interpretar este derecho de forma más extensiva. En el caso niños de la calle se formuló por primera vez un concepto que después sería frecuentemente utilizado y profundizado: el derecho a una "vida digna”, que configuraría la existencia de condiciones mínimas de seguridad y satisfacción de las necesidades económicas básicas. ${ }^{44}$

La primera vez que se aplica esta interpretación a los pueblos indígenas y tribales es en Yakie Axa vs. Paraguay. En el proceso se acreditó que los miembros de esta comunidad vivían en condiciones de miseria extrema a causa de la precariedad del asentamiento temporal donde se vieron obligados a permanecer, a la espera de la resolución de su solicitud de reivindicación de tierras. Posteriormente, en Xákmok Kásek vs. Paraguay, la Corte IDH explicó más específicamente lo que entiende por el derecho a la vida digna de los pueblos indígenas y tribales, señalando que este concepto equivale a la satisfacción de un conjunto de condiciones mínimas: acceso y calidad del agua, alimentación por sobre los estándares de desnutrición, servicios de salud próximos y respetuosos de los usos y costumbres tradicionales y un sistema educativo sensible a las diferencias culturales.

El último hito jurisprudencial en esta línea es el caso Miembros de la Asociación Lhaka Honhat (Nuestra Tierra) vs. Argentina (2020), donde vincula la idea en comento a los derechos a un medio ambiente sano, a una alimentación adecuada, al agua y a participar de una vida cultural. Es interesante constatar como la Corte IDH es consciente del problema, pues a pesar

44 Véanse el caso de los "Niños de la calle", sentencia del 19 de noviembre de 1999 (Villagrán Morales y otros), párr. 144, y el caso del “Instituto de Reeducación del Menor”, sentencia del 2 de septiembre de 2004, serie C, núm. 112, párr. 156. 
de que resuelve condenar al Estado e imponer una larga lista de medidas reparatorias (algunas incluso implican el desplazamiento de la población a otros territorios), por primera vez incluye un inédito reconocimiento de lo difícil que puede resultar para Argentina el cumplir con las medidas decretadas (párr. 323).

Dentro de este mismo contexto existió otra línea que la Corte IDH intentó desarrollar, lo que indica que los dos problemas estudiados tienden a confluir. En Moiwana vs. Surinam el concepto de vida digna estaba provisto de un contenido cultural específico. Al respecto, el voto particular del juez Cançado Trindade se explaya sobre el particular, aduciendo la existencia en la CADH de un "derecho a un proyecto de post-vida", el que tiene en cuenta las relaciones de los vivos con los muertos. En palabras de dicho juez:

En el cas d'espèce, me da la impresión de que los N'djukas tienen derecho a apreciar su proyecto de post-vida, el encuentro de cada uno de ellos con sus antepasados, la relación armoniosa entre los vivos y los muertos. Su visión de vida y post-vida abriga valores fundamentales, largamente olvidados y perdidos por los hijos e hijas de las "revoluciones" industriales y comunicativas (u otras involuciones, desde la perspectiva espiritual).

Esta interpretación del derecho a la vida digna tampoco logró trascender, aunque es interesante constatar que el voto particular parte por reconocer que se trata de una opinión de lege ferenda. Desde luego, la construcción es novedosa, al mismo tiempo que compleja. Probablemente, lo más cercano en términos teóricos es una concepción de justicia basada en la idea de reconocimiento, en la dirección propuesta por Nancy Fraser. ${ }^{45}$ Ahora bien, la manera como el juez Cançado Trindade traduce la idea de daño a ese "proyecto de post-vida” es la teoría del daño espiritual, que sería una categoría distinta del daño moral, destinado a indemnizar el sufrimiento. ${ }^{46}$

Al respecto, el voto particular plantea que, a diferencia del daño moral, que se enfoca en cuantificar el pretium doloris, el daño espiritual no es susceptible de indemnización pecuniaria, sino que precisa otro tipo de

45 Fraser, Nancy, "La justicia social en la era de la política de identidad: redistribución, reconocimiento y participación”, Revista de Trabajo, núm. 6, 2008, pp. 83-99.

46 Gómez, Fernando, “Daño moral”, InDret, núm. 1, 2000, disponible en: https: / /indret.com/ wp-content/themes/indret/pdf/006_es.pdf. 
reparación, la que, como se puede constatar de la siguiente cita, no parece nada sencilla, pues exige la preservación de la memoria histórica colectiva de los N'djuka contra el olvido: "en honor a sus muertos, protegiendo su derecho de vida lato sensu, incluyendo el derecho a una identidad cultural, que se manifiesta en sus reconocidos lazos de solidaridad con los muertos".

\section{VALORACIÓN CRÍTICA Y CONCLUSIONES}

No se puede concluir este estudio sin una valoración general de lo expuesto. Sin duda alguna, no se puede negar la trascendencia de las sentencias analizadas. En primer lugar, la jurisprudencia de la Corte IDH ha tenido un importante rol simbólico en el reconocimiento de los derechos de los pueblos indígenas y tribales. En segundo lugar, esta jurisprudencia también ha producido efectos tangibles que han significado avances importantes, que de otro modo no habrían sido posibles. Probablemente, no existe otro foro en el continente que haya expuesto, con la contundencia con que la Corte IDH lo ha hecho, las situaciones de despojo y vulneración de derechos a las que han sido sometidos los pueblos indígenas y tribales por los Estados nacionales de nuestro continente.

Sin embargo, en la actualidad y en la medida en que en América Latina se ha experimentado un resurgimiento de las reivindicaciones de los pueblos indígenas y tribales, los que rechazan la asimilación, afirman sus raíces y reclaman sus derechos, es necesario relevar qué es lo que se puede obtener del SIDH, teniendo en cuenta sus virtudes y limitaciones. En efecto, de este estudio se puede concluir que el potencial que posee el SIDH como agente de denuncia es enorme, mas sería engañoso pensar que puede proveer todas las soluciones a los problemas que afectan a dichos pueblos.

La experiencia latinoamericana es rica en problemas jurídicos originados del entrelazamiento entre órdenes normativos nativos y órdenes constitucionales de los Estados. Ello es un poderoso incentivo para diversificar las estrategias de emancipación de los pueblos indígenas y tribales y la promoción de sus formas de vida. Desde luego, el recurso a los derechos humanos, entendidos de acuerdo con la teoría estándar, es una de esas opciones. No obstante, como se ha puesto en evidencia a lo largo de estas páginas, las 
limitaciones que presenta el discurso de los derechos es un incentivo para diversificar las alternativas en insistir en discursos alternativos, no renunciando a la posibilidad de articular instituciones jurídicas originales, que permitan satisfacer las demandas de justicia de grupos humanos con cosmovisiones distintas a la eurocéntrica.

En las sentencias analizadas se hacen evidentes las limitaciones del discurso de los derechos humanos. Esto explica que la Corte IDH se ha visto en la necesidad de compatibilizar formas completamente distintas de entender la justicia, pero también de reparar injusticias profundas e históricamente asentadas, lo que, por supuesto, representa una tarea dantesca. Frente a este panorama, la Corte IDH se ha visto enfrentada a un dilema que se compone de dos partes: decidir entre lo ortodoxo o lo original, entre lo ambicioso y lo realista. En realidad, ello no hace más que confirmar que el derecho internacional no puede sino ser entendido como un ordenamiento de mínimos, pero también siempre como un recurso que sólo puede operar en subsidio de los mecanismos estatales.

Finalmente, y más allá de lo estrictamente jurídico, es necesario pensar en una adecuada estrategia diversificada de emancipación de los pueblos indígenas. En este sentido, es imperativo que la política ordinaria, la educación y la cultura sean estructuradas más allá del individualismo, el Estado y el mercado. Esto último es la única manera de reconocer un valor intrínseco a las cosmovisiones indígenas, al mismo nivel que la forma moderna, europea y colonial de ver el mundo, y, en definitiva, reivindicar el hecho de que una sociedad que niega su diversidad no hace sino cercenar parte importante de su capital cultural.

\section{BIBLIOGRAFÍA}

ANTKOWIAK, Thomas, "A Dark Side of Virtue: The Inter-American Court and Reparations for Indigenous Peoples”, Duke Journal of Comparative \& International Law, vol. 25, 2014.

Arai-TAKahashi, Yutaka, The Margin of Appreciation Doctrine and the Principle of Proportionality in the Jurisprudence of the ECHR, Amberes, Intersentia, 2002. 
BLANCO, Jesús, "Las concepciones del ius naturale o los fundamentos de la política en Grocio, Hobbes y Espinoza”, Papeles de Filosofía, vol. 22, núm. $1,2003$.

BURGER, Julian, "La protección de los pueblos indígenas en el sistema internacional", Derechos humanos de los grupos vulnerables, Barcelona, Universitat Pompeu Fabra, 2014.

Cavallaro, James y Brewer, Stephanie, "Reevaluating Regional Human Rights Litigation in the Twenty-First Century: The Case of the InterAmerican Court", The American Journal of International Law, vol. 102, 2008.

Cimadamore, Alberto et al., Pueblos indígenas y pobreza. Enfoques multidisciplinarios, Buenos Aires, Clacso, 2006.

Contreras, Pablo, "Control de Convencionalidad, deferencia internacional y discreción nacional en la jurisprudencia de la Corte Interamericana de Derechos Humanos”, Ius et Praxis, vol. 20, núm. 2, 2014.

DonnNelly, Jack, "The Relative Universality of Human Rights", Human Rights Quarterly, vol. 29, núm. 2, 2007.

Engle, Karen, "On Fragile Architecture: The UN Declaration on the Rights of Indigenous Peoples in the Context of Human Rights", The European Journal of International Law, vol. 22, núm. 1, 2011.

EsTUPIÑAn, Rosmerlin, "Pueblos indígenas y tribales: la construcción de contenidos culturales inherentes en la jurisprudencia interamericana de derechos humanos", Anuario Mexicano de Derecho Internacional, vol. XIV, 2014.

EsTUPIÑAN, Rosmerlin e IBÁÑEZ, Juana, "La jurisprudencia de la Corte Interamericana de Derechos Humanos en materia de pueblos indígenas y tribales", Derechos humanos de los grupos vulnerables, Barcelona, Universitat Pompeu Fabra, 2014.

FISS, Owen, "Libertad de expresión y estructura social”, en ÁviLA, María et al. (ed.), Libertad de expresión: debate, alcances y nueva agenda, Quito, Unesco, 2011.

FERNÁNDEZ, Eusebio, "El problema del fundamento de los derechos humanos", Anuario de Derechos Humanos, 1982.

FraSer, Nancy, "La justicia social en la era de la política de identidad: redistribución, reconocimiento y participación”, Revista de Trabajo, núm. 6, 2008.

GuZmán, Alejandro, "Historia de la denominación del derecho-facultad como «subjetivo»", Revista de Estudios Histórico-Jurídicos, núm. 25, 2003. 
LA RuE, Frank, "Libertad de expresión de los pueblos indígenas, minorías y grupos vulnerables”, en ÁviLA, María et al. (eds.), Libertad de expresión: debate, alcances y nueva agenda, Quito, Unesco, 2011.

GÓmEZ, Fernando, "Daño moral”, InDret, núm. 1, 2000, disponible en: https: / /indret.com/wp-content/themes/indret/pdf/006_es.pdf.

HITTERS, Juan, “ ¿Son vinculantes los pronunciamientos de la Comisión y de la Corte Interamericana de Derechos Humanos? (Control de constitucionalidad y convencionalidad)", Revista Iberoamericana de Derecho Procesal Constitucional, núm. 10, 2008.

Kymlicka, Will, Multicultural Citizenship. A Liberal Theory of Minority Rights, Oxford University Press, 1995.

MACK, Johnny, "Hoquotist: Reorienting through Storied Practice", en LESSARD, Hester et al. (eds.), Narratives of Contact and Arrival in Constituting Political Community, Vancouver, University of British Columbia Press, 2011.

Mereminskaya, Elina, "El Convenio 169 de la OIT sobre Pueblos Indígenas y Tribales. Derecho Internacional y experiencias comparadas", Estudios Públicos, núm. 121, 2011.

NúÑEZ, Manuel, "Sobre la doctrina del margen de apreciación nacional. La experiencia latinoamericana confrontada y el thelos constitucional de una técnica de adjudicación del derecho internacional de los derechos humanos", en ACOSTA, Paola y NúÑEZ, Manuel (coords.), El margen de apreciación en el Sistema Interamericano de Derechos Humanos: proyecciones regionales y nacionales, México, UNAM, Instituto de Investigaciones Jurídicas, 2012.

PAul, Álvaro, "La Corte Interamericana in vitro: comentarios sobre su proceso de toma de decisiones a propósito del caso Artavia”, Derecho Público Iberoamericano, núm. 2, 2013.

Neuman, Gerald, "Import, Export, and Regional Consent in the InterAmerican Court of Human Rights", European Journal of International Law, vol. 19, núm. 1, 2008.

POVINELl, Elizabeth, The Cunning of Recognition, Durham, Duke University Press, 2002.

Rawls, John, The Law of the People, Harvard University Press, 2001.

RISSE, Thomas y SIKKINK, Kathryn, "The Socializations of International Human Rights Norms into Domestic Practices: Introduction”, en RISSE, 
Thomas et al. (eds.), The Power of Human Rights. International Norms and Domestic Change, Cambrige University Press, 1999.

RODRÍGUEZ-PIÑEIRO, Luis, "El sistema interamericano de derechos humanos y los pueblos indígenas”, en Berraondo, Mikel (coord.), Pueblos indígenas y derechos humanos, Bilbao, Universidad de Deusto, 2006.

SÁnchez Curihuentro, Juan, "El Az Mapu o sistema jurídico mapuche", Revista CREA, núm. 2, 2001.

SAUCA, José María y WenCES, Isabel, "Derechos colectivos (en la doctrina de la Corte Interamericana de Derechos Humanos)", EUNOMÍA. Revista en Cultura de la Legalidad, 2015.

SCHÖNSTEINER, Judith, "Dissuasive Measures and the Society as a Whole: A Working Theory of Reparations in the Inter-American Court of Human Rights", American University International Law Review, vol. 23, 2007.

SCHÖNSTEINER, Judith y COUSO, Javier, "La implementación de las decisiones de los órganos del Sistema Interamericano de Derechos Humanos en Chile: ensayo de un balance", Revista de Derecho Universidad Católica del Norte, año 22, núm. 2, 2015.

Sousa SANTOS, Boaventura de, Descolonizar el saber, reinventar el poder, Santiago de Chile, LOM Editores, 2013.

STAVENHAGEN, Rodolfo, "Identidad indígena y multiculturalidad en América latina", Araucaria. Revista Iberoamericana de Filosofía, Política y Humanidades, vol. 4, núm. 7, 2002.

THOM, Brian, "Reframing Indigenous Territories: Private Property, Human Rights and Overlapping Claims", American Indian Culture and Research Journal, vol. 38, núm. 4, 2014.

UNICEF, Atlas sociolingüistico de pueblos indígenas en América Latina, 2020.

VELASCO, Juan, "La noción republicana de ciudadanía y la diversidad cultural", Isegoría, núm. 33, 2006.

Witheley, Peter, "Do «Language Rights» Serve Indigenous Interests? Some Hopi and Other Queries", American Anthropologist, New Series, vol. 105, núm. 4, 2003. 